\title{
A Study on Process Characteristics and Performance of Hot Wire Gas Tungsten Arc Welding Process for High Temperature Materials
}

\author{
Anantha Padmanaban MR ${ }^{*}$, Baskar Neelakandan ${ }^{a}$, Devakumaran Kandasamy ${ }^{b}$ \\ ${ }^{a}$ Department of Mechanical Engineering, Saranathan College of Engineering, Trichy, Tamil Nadu, India \\ ${ }^{b}$ Welding Research Institute, Bharath Heavy Electricals Limited, Trichy, Tamil Nadu, India
}

Received: April 23, 2016; Revised: August 11, 2016; Accepted: September 7, 2016

\begin{abstract}
Hot wire gas tungsten arc welding (HW-GTAW) process is the one where the filler wire is preheated close to its melting point before it is fed in to the arc. The effect of HW-GTAW parameters such as welding current, hot wire current and the wire feed rate during welding of super ASS 304H stainless steel tubes were evaluated in terms of heat input, voltage-current (V-I) characteristics and weld bead characteristics such as bead weight and geometry. The results obtained indicate that for a constant welding current, increasing the hot wire current and wire feed rate provides a stable V-I characteristics and higher bead weight. Further, increasing the hot wire current and wire feed rate also provides better or desired weld pool and hence the bead geometry was described in terms of width, penetration depth, area of fusion and toe angle. By utilising the above knowledge, the tube to tube butt welding of SS $304 \mathrm{H}$ material was carried out. It was observed that, the weld joint is qualified as per the quality requirement of ASME: Sec IX standard.
\end{abstract}

Keywords: Super 304H, Hot wire, Bead geometry, Heat input

\section{Introduction}

Hot wire gas tungsten arc welding (HW-GTAW) process is a modified gas tungsten arc welding (GTAW) process in which the filler wire is pre-heated before entering the weld pool ${ }^{1}$. As the filler wire is pre-heated, the weld deposition efficiency of HW-GTAW process is higher when compared to the conventional GTAW process. HW-GTAW process is specifically used to weld many high temperature materials that are used by the power industry ${ }^{2,3}$. It is a known fact that the quality of a weld joint is influenced by the welding parameters. In conventional GTAW there are three primary variables viz., arc voltage (V), welding current (I) and travel speed which determine the heat input of the process ${ }^{4}$. In case of HW-GTAW process, as the filler wire is resistance heated before entering the weld pool, the current used to heat the filler wire, referred as hot wire current also influences the quality of welding. The voltage (V) - current (I) characteristics of the power source may also change and accordingly influence the performance of the HW-GTAW process. Though many research work has been carried out on evaluating the V-I characteristics and its influence on weld quality in conventional GTAW ${ }^{5,6}$, studies on HW-GTAW process are rather sparse ${ }^{7}$. The reason being, HW-GTAW can be carried out only in automated or mechanised conditions which can exercise control over welding parameters like arc voltage (V), wire feed rate (WFR), hot wire current $\left(\mathrm{I}_{\text {hot }}\right)$ and welding current (I) to provide a desired stable arc under dynamic operating conditions of welding. In addition, adequate V-I characteristics also required for the filler metal

\footnotetext{
* e-mail: mrpadmanaban-mech@saranathan.ac.in
}

melting requirements. As the existing information on this process is limited, it is imperative to study the individual and synergistic effect of HW-GTAW process variables such as welding current, hot wire current and wire feed rate on the weld quality.

In the current work, the effect of the aforementioned process variables of HW-GTAW of super $304 \mathrm{H}$ stainless steel tube used for boiler manufacturing has been evaluated by characterising the welding process and joint for (a) heat input (b) V-I characteristics (c) weight of the metal deposited and (5) bead geometry described in terms of bead width, depth of penetration, area of fusion and deposit, toe angle. By utilising the above knowledge, optimised HW-GTA welding parameters were derived for production of tube to tube butt weld joint of super $304 \mathrm{H}$ material. Further, the mechanical and metallurgical properties of the weld joint studied as per the quality requirements of ASME: Sec IX standard. The results obtained are presented and discussed here.

\section{Experimental}

\subsection{Material}

The material used for the study is super $304 \mathrm{H}$ austenitic stainless steel tube with a thickness of $4.5 \mathrm{~mm}$ and $63.4 \mathrm{~mm}$ outer diameter. The nominal composition of the material is shown in Table 1. This material is widely used in high temperature regions of boiler that are exposed to a temperature of $550-650^{\circ} \mathrm{C}$. The microstructure of as-received tube shown in Figure 1 exhibits austenitic grains with $\mathrm{MC}$ precipitate (Mainly $\mathrm{M}_{23} \mathrm{C}_{6}$ ). 
Table 1: Chemical composition of base metal and filler wire.

\begin{tabular}{lcccccccccccccc}
\hline \multirow{1}{*}{ Materials } & \multicolumn{1}{c}{ Chemical composition (Wt. \%) } & & & & & & & \\
& $\mathrm{C}$ & $\mathrm{Si}$ & $\mathrm{Mn}$ & $\mathrm{Cr}$ & $\mathrm{Ni}$ & $\mathrm{Cu}$ & $\mathrm{Ti}+\mathrm{V}+\mathrm{Nb}$ & $\mathrm{N}$ & $\mathrm{P}$ & $\mathrm{S}$ & $\mathrm{Mo}$ & $\mathrm{B}$ & $\mathrm{Others}$ \\
\hline $\begin{array}{l}\text { SS304H Base } \\
\text { Metal }\end{array}$ & 0.08 & 0.22 & 0.79 & 17.74 & 8.58 & 2.68 & 0.62 & 0.11 & 0.015 & $<0.01$ & 0.35 & $<0.001$ & $\mathrm{Fe}, \mathrm{Bal}$. \\
ER:SS304H Filler & 0.06 & 0.28 & 3.2 & 17.27 & 16.47 & 2.74 & 0.2 & 0.14 & $<0.01$ & $<0.01$ & 0.94 & $<0.001$ & $\mathrm{Fe}, \mathrm{Bal}$. \\
\hline
\end{tabular}

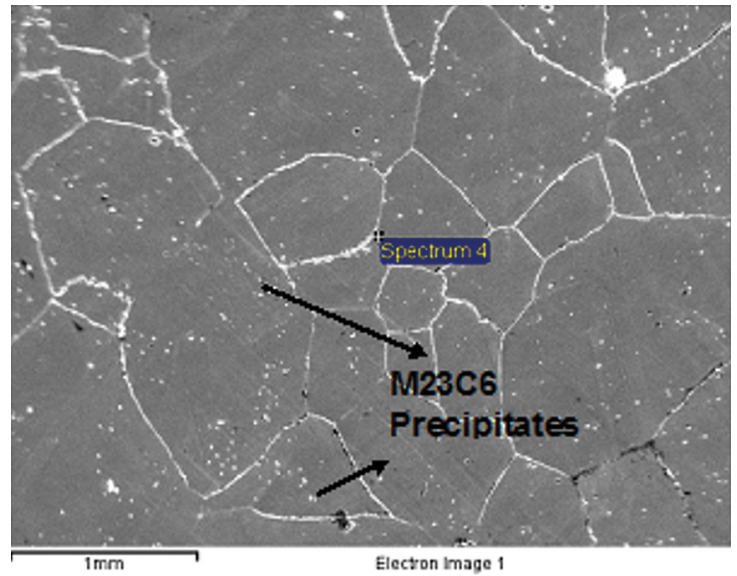

Figure 1: Typical microstructure of base metal.

\subsection{HW-GTA welding}

Hot Wire Gas Tungsten Arc (HW-GTA) welding on $304 \mathrm{H}$ austenitic stainless steel (ASS) was carried out using $1.0 \mathrm{~mm}$ diameter austenitic stainless steel wire of grade ER: 304H (Table 1) with Panasonic-YC400 direct current (DC) welding power source. During the welding process, the tube was rigidly fixed in a fully automated welding lathe that has synchronised rotation of head and tail stock. The welding power source, welding torch, mechanised hot wire feeder and automatic torch positioning system were fitted on welding lathe as shown in Figure 2. The welding parameters such as welding current (I), wire feed rate (WFR), hot wire current $\left(\mathrm{I}_{\text {hot }}\right)$, welding speed, filler wire extension and arc gap were programmed and controlled using the control panel attached with the welding lathe. Entire operation of HW-GTAW was monitored and controlled using a M/s. W.Tech make PLC programmer. Commercial pure argon (99.98\%) shielding gas was passed at $15 \mathrm{lpm}$ during the welding operation. Prior to welding, the base metal was cleaned with acetone. The welding parameters used for the current are listed in Table 2. Weld bead deposition or welding was carried out over the entire $\left(360^{\circ}\right)$ diameter of tube. welding process and joint for heat input, V-I characteristics, weight of the metal deposited and bead geometry described in terms of bead width, depth of penetration, area of fusion and deposit, toe angle.

Based on the bead on tube studies, the optimised HWGTA welding parameters were derived is given in Table 3. By using Table 3 welding parameters, tube to tube butt welding of super $304 \mathrm{H}$ has been carried out using same grade of filler wire (Table 1) under commercial pure argon gas shielding environment.

\subsubsection{Estimation of Heat Input}

The effect of HW-GTAW process variables on the heat input (HI) of hot wire GTAW process has been estimated by considering energy produced through welding arc and hot wire addition as follows?.

$$
\mathrm{HI}=\frac{I_{h o t}^{2} R_{h}}{V_{w}}+\frac{V I}{S}
$$

where, I is welding current, $\mathrm{I}_{\text {hot }}$ is hot wire current, $\mathrm{V}$ is arc voltage, $S$ is welding speed $(\mathrm{cm} / \mathrm{min}), \mathrm{V}_{\mathrm{w}}$ is wire feed speed $(\mathrm{m} / \mathrm{min})$ and $R_{h}$ is resistance of filler wire $(\Omega)$. $R_{h}$ can be estimated by considering resistivity of filler material ( $\rho$, $\Omega \mathrm{m}$ ), filler wire extension ( $\mathrm{L}, \mathrm{mm}$ ) and cross sectional area of filler wire $\left(\mathrm{A}_{\mathrm{w}}, \mathrm{mm}^{2}\right)$ as shown below ${ }^{9}$.

$$
R_{h}=\frac{\rho L}{A_{w}}
$$

For AWS: ER 304H grade filler metal, the resistivity $\rho$ is considered as $6.47 \times 10^{-7} \Omega \mathrm{m}^{9}$.

\subsubsection{Studies on V-I Characteristics}

The effect of hot wire welding parameters on change in arc voltage (V) and welding current (I) during welding was measured with the help of weld data acquisition software connected to HW-GTAW system.

\subsubsection{Studies on Performance of $H W-G T A W$ Process}

The performance of HW-GTAW process under different welding current, hot wire current and wire feed rate were studied by measuring the weight of weld metal deposited (WD) and bead geometry. The WD is measured as weight of material before and after welding by using weighing machine having least count of $0.001 \mathrm{~g}$. The geometry of weld bead was also evaluated on polished and etched $(10 \%$ Oxalic Acid) transverse section of weld bead as schematically represented in Figure 3.

\subsubsection{Studies on Weld Joint Characteristics}

The metallurgical characteristics of tube weld joint have been studied under optical microscope with respect to the microstructure of weld/HAZ and revealed in its metallographic 


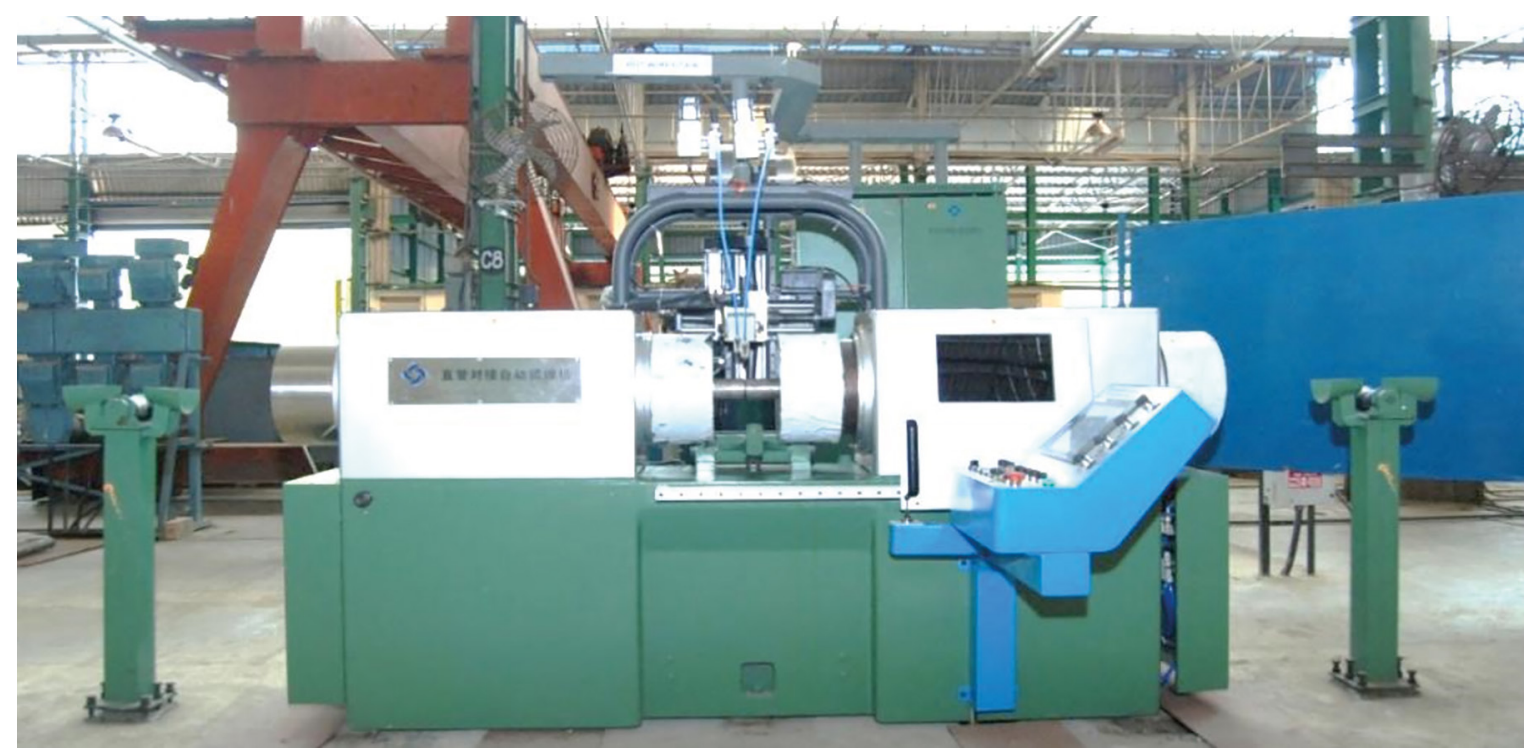

Figure 2: Photograph of HW-GTAW setup.

polished and etched (10\% Oxalic Acid) transverse section of weld joint. The mechanical properties such as tensile, bend and hardness across the weld joint have been carried out as per the standard requirement of ASME: Sec IX.

\section{Results and Discussion}

During HW-GTAW using the process parameters listed in Table 2, it was observed that, for a WFR of $2000 \mathrm{~mm} / \mathrm{min}$, the welding arc was stable only at higher welding current of 150 A irrespective of hot wire current. Further, it was also observed that while varying the welding current, the arc length was not uniform throughout the weld length for a given hot wire current of $80 \mathrm{~A}$, and WFR of $1500 \mathrm{~mm} / \mathrm{min}$. This results in irregular bead profiles as shown in Figure $4 \mathrm{a}$ and $4 \mathrm{~b}$. Therefore, in the current study, on those conditions of wire feed rate, welding current and hot wire current that produces a stable arc and visibly acceptable weld bead profile were considered for further investigation.

\subsection{Heat Input}

During hot wire GTAW process, two heat sources of different nature act concurrently on weld pool. One is a continuous heat source (arc heat source) of double ellipsoidal nature acting at the surface of base plate, which melts and produces an initial weld pool in the base metal. The other is a resistance heating of filler metal (Q) and it is considered as a point heat source dictating the weld size and deposit over the initially developed by the arc heating. It is well known that, the resistance heating of filler wire can be varied by varying hot wire current $\left(\mathrm{I}_{\text {hot }}\right)$ and filler wire extension (L). Under these circumstances, the effect of ' $L$ ' on resistance heating produced under different hot wire current has been studied and it is shown in Figure 5. It is observed that, at a given hot wire current, increase of ' $L$ ' enhances Q. Further, it is noticed that, at a given ' $\mathrm{L}$ ', increase of $\mathrm{I}_{\text {hot }}$ also enhances the $\mathrm{Q}$. The correlation of $\mathrm{Q}$ as a function of ' $\mathrm{L}$ ' and $\mathrm{I}_{\text {hot }}$ is given by equation (3) and it is maintaining the coefficient of 0.99 . The correlation can be used to estimate the precise heat input of the HW-GTAW process in welding of Super 304H material.

$$
\begin{aligned}
Q= & 0.00038+0.00000273 I_{\text {hot }}- \\
& 8.168 L+0.177 I_{\text {hot }} \quad(3)
\end{aligned}
$$

\subsection{V-I Characteristics}

V-I Characteristics of HW-GTAW process under different hot wire current and wire feed rate has been shown in Figures 6 (a-c). It can be seen that V-I characteristics of HW-GTAW process varies insignificantly irrespective of changes in hot wire current and wire feed rate. This may be considered as an advantage of hot wire GTAW process over the conventional GTAW with respect to consistent energy transfer from electrode to the weld pool. Therefore, it is inferred that the HW-GTAW process instead of conventional GTAW process may provide comparatively stable arc which may be beneficial for improved weld quality. However from Figure $6 \mathrm{c}$, it is further noticed that at higher wire feed rate of $2000 \mathrm{~mm} /$ min, the V-I characteristics stable only at higher welding current of $150 \mathrm{~A}$ irrespective of changes in hot wire current. This behaviour indicated that when wire feed rate increases, arc energy produced at less than $150 \mathrm{~A}$ is not sufficient to melt the filler wire which results in an unstable arc during welding irrespective of changes 
Table 2: Welding parameters used in weld bead on tube deposition by HW-GTAW process.

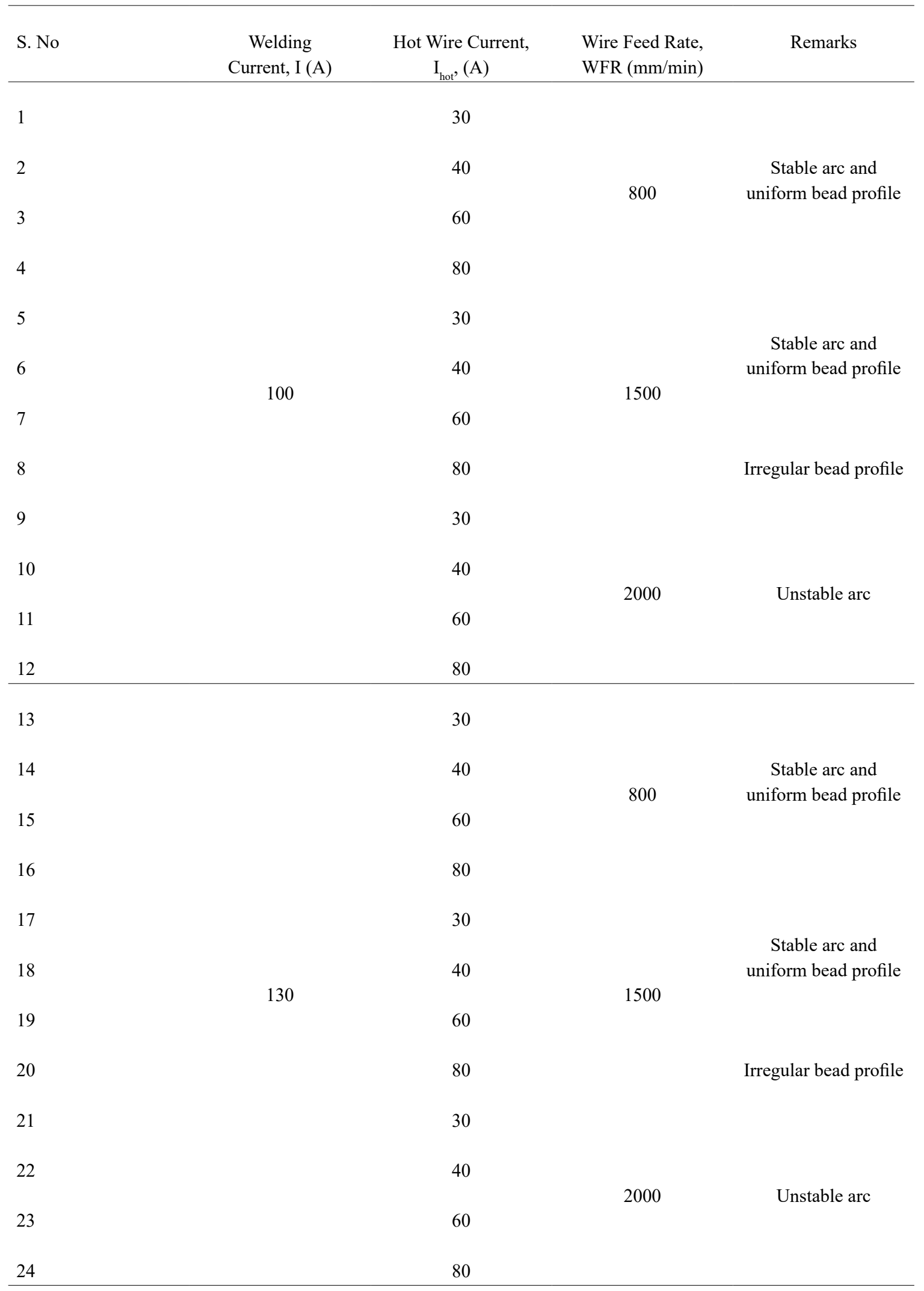


Stable arc and uniform bead profile
Stable arc and uniform bead profile
Irregular bead profile

Stable arc and irregular bead profile

Table 3: Optimised HW-GTA welding parameter used for preparation of tube to tube butt welding of Super 304H material.

\begin{tabular}{llll}
\hline Welding Current, I (A) & Hot Wire Current, $\mathrm{I}_{\text {hot }}(\mathrm{A})$ & Wire Feed Rate, WFR $(\mathrm{mm} / \mathrm{min})$ & Weld pass \\
\hline 100 & 40 & 800 & Root pass \\
130 & 60 & 800 & Hot pass \\
130 & 60 & 1500 & Subsequent weld passes \\
\hline
\end{tabular}

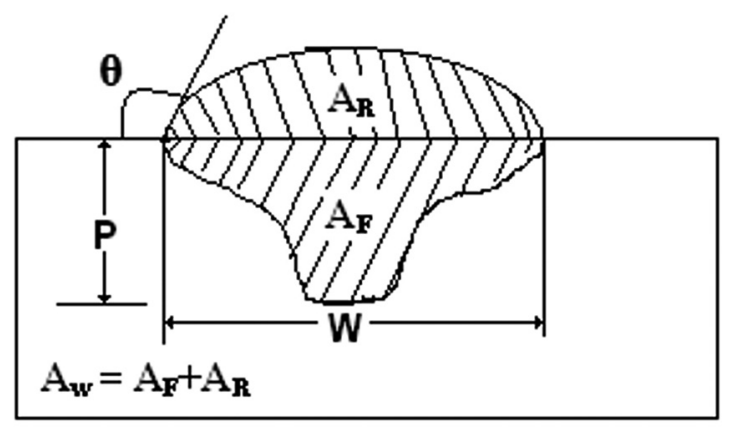

Figure 3: Schematic diagram showing geometry of weld bead.

in hot wire current. Hence, further analysis on welding performance and geometry of hot wire GTAW process are studied only at the wire feed rate of 800 and 1500 $\mathrm{mm} / \mathrm{min}$. In addition, increase of hot wire current in the filler metal causes arc deflection especially, where WFR is beyond $800 \mathrm{~mm} / \mathrm{min}$, it is due to internal magnetic field developed around the welding arc and pushing the weld pool under the arc. This is in agreement with the results reported in the literature ${ }^{10}$.

\subsection{Performance of $H W$-GTAW Process}

Typical photographs of weld bead and its transverse section of weld deposit at a given hot wire current and WFR of $30 \mathrm{~A}$ and $800 \mathrm{~mm} / \mathrm{min}$ respectively under different welding current have been shown in Figure 7 (a-c) \& Figure 8 (a-c). It is observed that the performance of weld bead with respect to weld pool shape and size varied significantly with increase of welding current. Further, it is also observed that, the area of heat affected zone of base metal increases with increase of welding current (Figure 8). The detailed discussions are as follows. The effect of variation in welding current and hot wire current in the range of 100-150 A and 30-80 A respectively on measured weight of weld deposition under different wire feed rate of 800 and $1500 \mathrm{~mm} / \mathrm{min}$ has been shown in Figure 9 (a)\& Figure 9(b) respectively. It has been observed that at any hot wire current, weight of weld deposition increases with the increase in welding current irrespective of keeping wire feed rate at the relatively low and high levels. However, the figures further show that at a given welding current, the increase of hot wire current and wire feed rate enhances the weight of weld deposition 


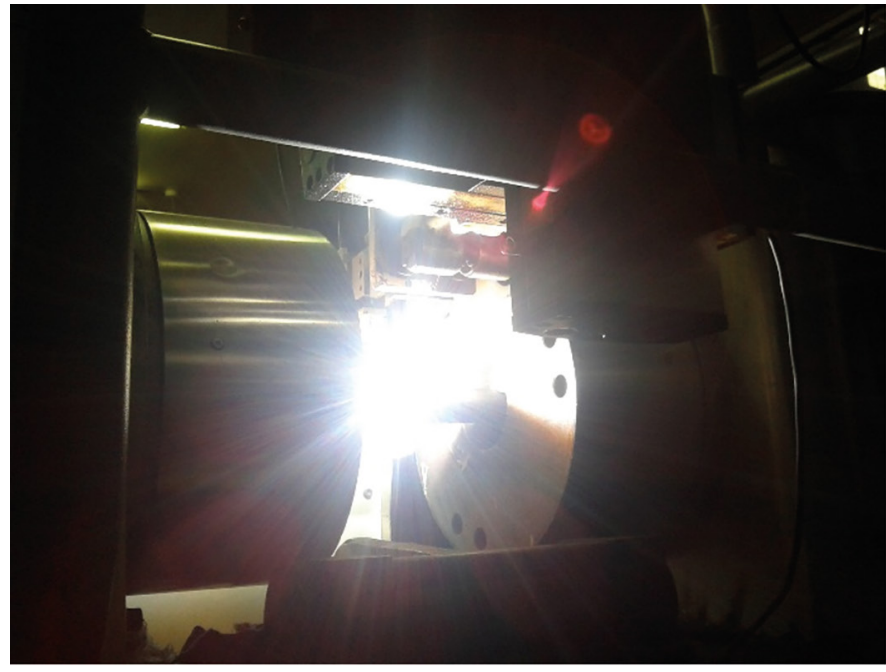

(a)

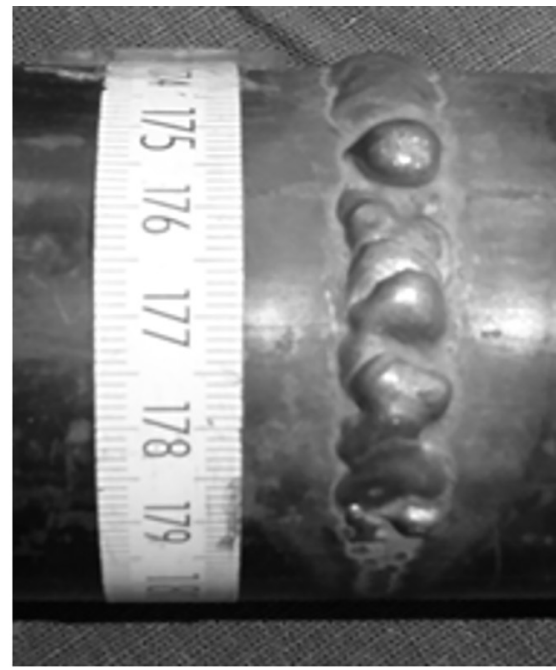

(b)

Figure 4: (a) Typical photograph showing unstable arc behaviour during welding at a given WFR and welding currrent of $2000 \mathrm{~mm} / \mathrm{min}$ and 100A respectively. (b) Typical photograph showing irregular bead profile at a given hot wire current of $80 \mathrm{~A}$ and WFR of $1500 \mathrm{~mm} / \mathrm{min}$.

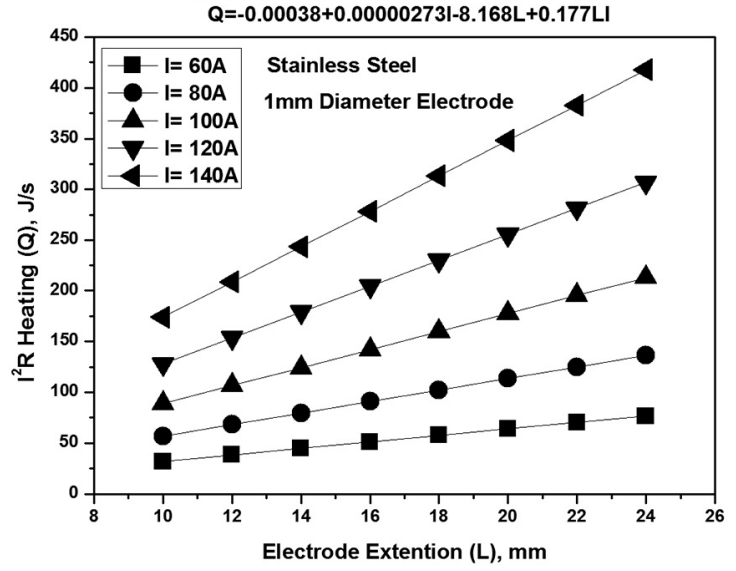

Figure 5: Effect of filler wire extension on resistance heating generated under different hot wire current.

significantly. In hot wire GTAW process, filler wire is resistance heated till close to the melting point and added to the weld pool behind the tungsten electrode. This allows the filler metal to flow across the weld puddle resulting in an increase of weight of weld deposition. Due to pre-heating of filler wire, relatively more wire feed rate can be introduced in HW-GTAW than in conventional GTAW. This behaviour is in agreement with the earlier work in case of welding of plain low carbon steel ${ }^{10}$.

The effect of variation in welding current (100 -150 A) and hot wire current (30-80 A) on measured bead width under different wire feed rate of 800 and $1500 \mathrm{~mm} / \mathrm{min}$ are shown in Figure 10(a) \& Figure 10(b) respectively. It is observed that at any hot wire current, bead width increases significantly with the increase of welding current irrespective of keeping wire feed rate at the relatively low and high levels.
However the figure further shows that at a given welding current the increase of wire feed rate increases bead width significantly. Such a variation in bead width as a function of welding current, hot wire current and wire feed rate may primarily be attributed to variations in heat transfer to weld pool through arc and resistance heating of filler metal affecting the fluidity of its molten weld pool. Increase in hot wire current also increases resistance heating of filler wire which may accelerate significant weld deposition rate resulting in a lateral displacement of liquid in weld pool and accordingly enhances weld bead width.

In the line of the earlier observation on bead width (Figure 10) the variation is measured as depth of penetration of weld deposit under the same range of welding current and hot wire current as and it is shown in Figure 11(a) \& Figure 11(b) at different wire feed rate of 800 and 1500 $\mathrm{mm} / \mathrm{min}$ respectively. The figure shows that at a given hot wire current and wire feed rate the increase of welding current is showing irregular variation in it. Such a variation of depth of penetration with respect to welding current is in agreement with the observation on weld characteristic reported elsewhere in the case of GMAW and P-GMAW of various ferrous and non-ferrous materials ${ }^{11}$. It is also reported that depth of penetration is primarily attributed to the variation in arc heat and to some extent to variation in heat of filler metal transferred to the weld pool ${ }^{4,12}$. However, the influence of significant enhancement of arc pressure with the increase of welding current cannot be ignored. Further it is noticed that the depth of penetration also depends on the rate of weld metal deposition and fluidity of molten metal as well as arc characteristic.

Considering variation in bead width and depth of penetration of weld deposition, it may be interesting to study 


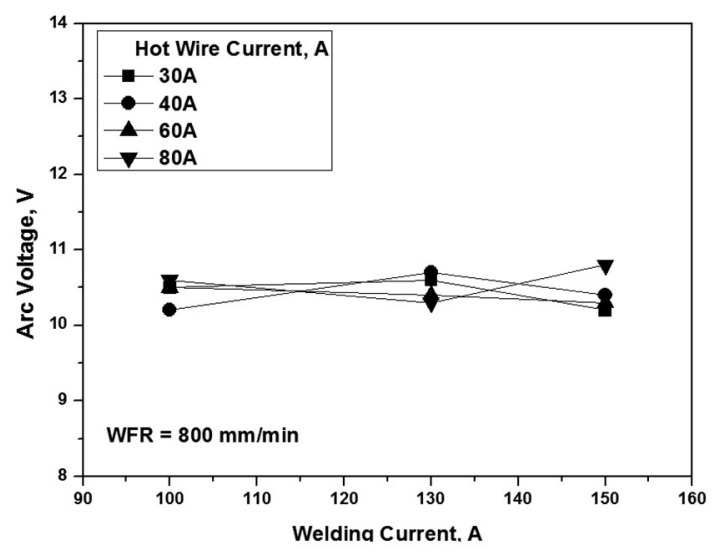

(a)

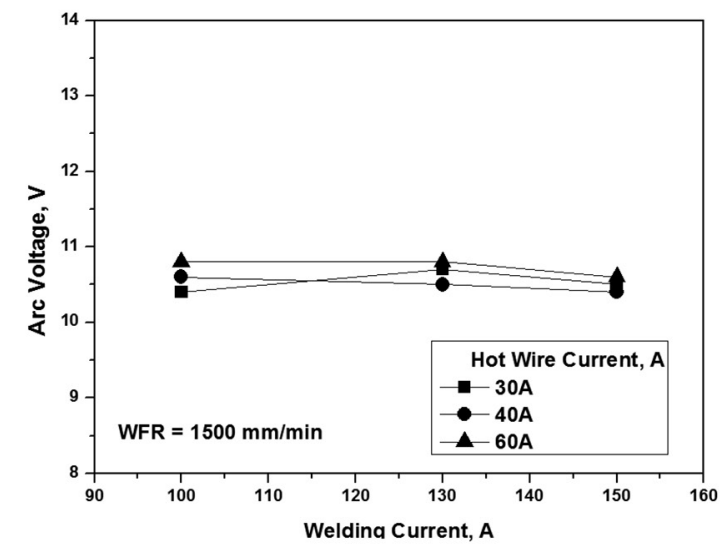

(b)

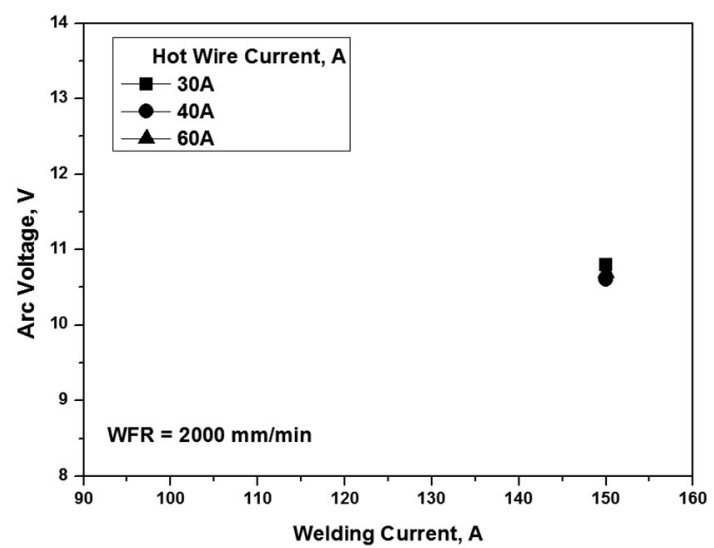

(c)

Figure 6: V-I characteristics of HW-GTAW process under different hot wire current and wire feed rate (a) $800 \mathrm{~mm} / \mathrm{min}$, (b) $1500 \mathrm{~mm} /$ $\mathrm{min}$ and (c) $2000 \mathrm{~mm} / \mathrm{min}$.

the area of fusion and area weld deposition to understand the advantage of HW-GTAW process. The effect of welding current on measured area of fusion and area of weld deposit under varying hot wire current in the range of 30-80 A at different wire feed rate of 800 and $1500 \mathrm{~mm} / \mathrm{min}$ have been shown in Figure 12(a \& b) and Figure 13(a\&b) respectively. The figures show that at a given hot wire current and wire feed rate the increase of welding current increases the area of fusion and area of weld deposition significantly. It may also be understood in the light of earlier discussion in the context of the variation in bead width and depth of penetration. As discussed above, geometrical characteristic of HW-GTA weld bead deposition on Super 304H ASS under different process parameters, it is understood that higher wire feed rate and welding current at any hot wire current gives comparatively higher areas of fusion and weld deposit.

A variation in toe angle in the weld deposition ultimately becomes responsible for the quality of weld joint. Therefore in the light of the observation of the area of fusion of the base metal and that of weld deposit, it is interesting to study their effect on toe angle of the bead and tube weld deposition on super $304 \mathrm{H} \mathrm{ASS}$ at different parameters with respect to the welding current and hot wire current and wire feed rate. The effect of welding current on measured toe angle under different hot wire current and wire feed rate is shown in Figure 14 (a \&b). As observed earlier here also the increase of welding current enhances the toe angle significantly. The figure further depicts that at given welding current and hot wire current the increase of wire feed rate decreases the toe angle. Such type of variation in toe angle as a function of welding current, hot wire current and wire feed rate may primarily result from the combined influence of both the areas of fusion and that of weld deposit (Figure 12 and Figure 13).

\subsection{Weld Joint Characteristics}

There are several austenitic stainless steel grades developed for modern ultra-super critical power plants viz., TP347H, Super $304 \mathrm{H}$ and ASS310S etc. ${ }^{13-15}$. Among 


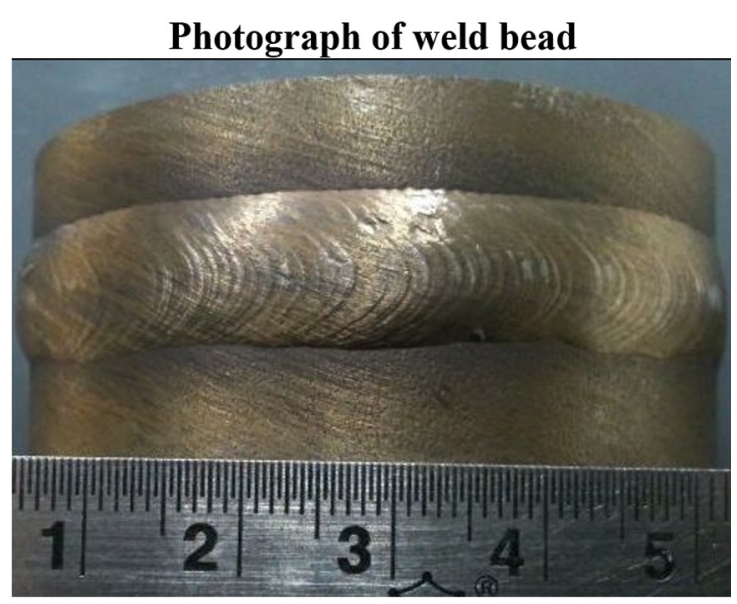

(a)

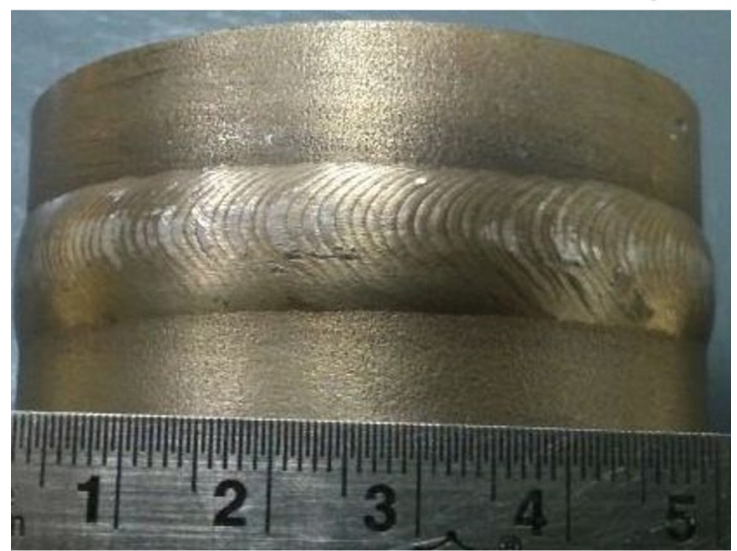

(b)

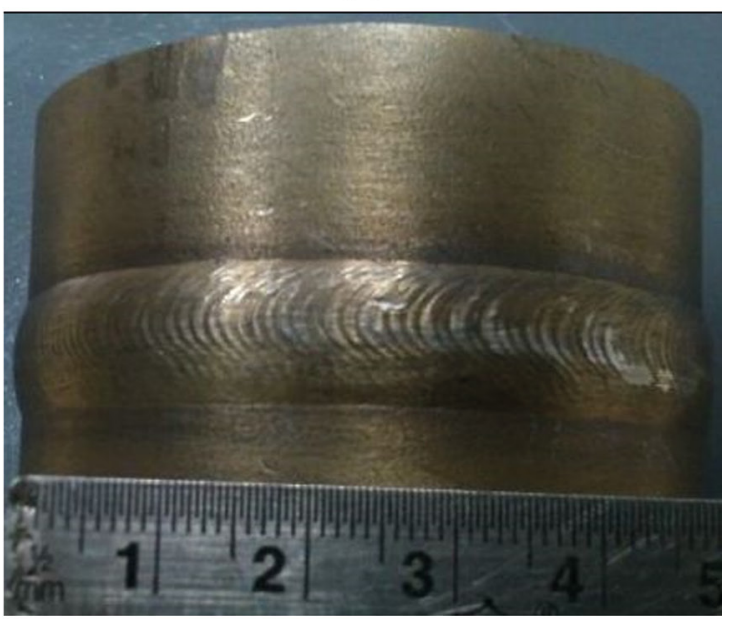

(c)

Figure 7: Typical photograph of weld bead at a given hot wire current and WFR of $30 \mathrm{~A}$ and $800 \mathrm{~mm} / \mathrm{min}$ respectively under different welding current of (a) 100A, (b) 130A and (c) 150A.

these materials Super $304 \mathrm{H}$ is widely used in super heater headers where the working temperature is between 450 $550^{\circ} \mathrm{C}^{2,14,16}$. One of the major limitations of welding of SS-304H material, is its susceptibility for hot cracking.

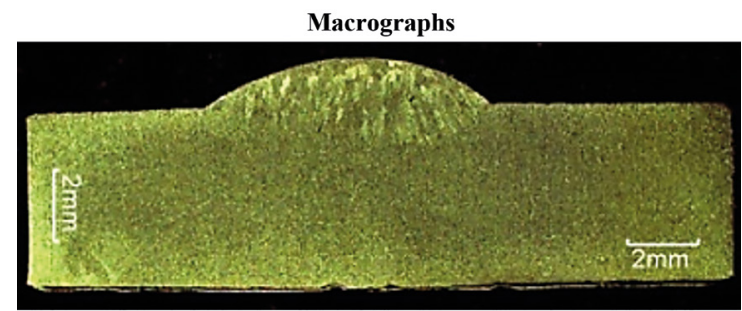

(a)

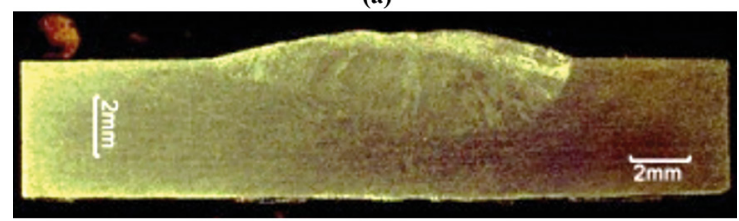

(b)

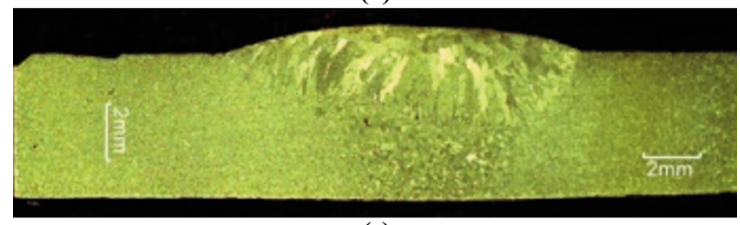

(c)

Figure 8: Typical macrograph of transverse section of weld deposit at a given hot wire current and WFR of $30 \mathrm{~A}$ and $800 \mathrm{~mm} /$ min respectively under different welding current of (a) 100A, (b) $130 \mathrm{~A}$ and (c) $150 \mathrm{~A}$.

The tendency of hot cracking enhances with an increasing brittle temperature range (BTR) between nil strength temperature and ductility recovery temperature ${ }^{14}$. The BTR largely depends on the heat input of the process. However, the use of HW-GTAW process in tube to tube butt welding of SS $304 \mathrm{H}$ materials shows improved the weld joint quality and also meeting the ASME sec IX standard requirements. The summarised results are presented in Table 4. Based on the above studies, it could be inferred that, the HW-GTAW process is a potential technique to control the hot cracking susceptibility and to improve the weld joint characteristics of SS-304H material.

\section{Conclusions}

From this investigation it is concluded that beyond the conventional welding parameters, the V-I characteristics and its performance of the HW-GTAW process can be manipulated with a change in hot wire current and wire feed rate. Such merits of HW-GTAW may be suitably exploited in advanced use of this process like welding of high temperature materials. The correlation of resistance heating of filler wire as a function of hot wire current and filler wire extension of HW-GTAW process may help to critically control the process in welding of Super $304 \mathrm{H}$ austenitic stainless steel material. Further, it is concluded that, the increase of hot wire current and wire feed rate enhances the weight of metal deposition and accordingly influence the geometry of weld bead. 


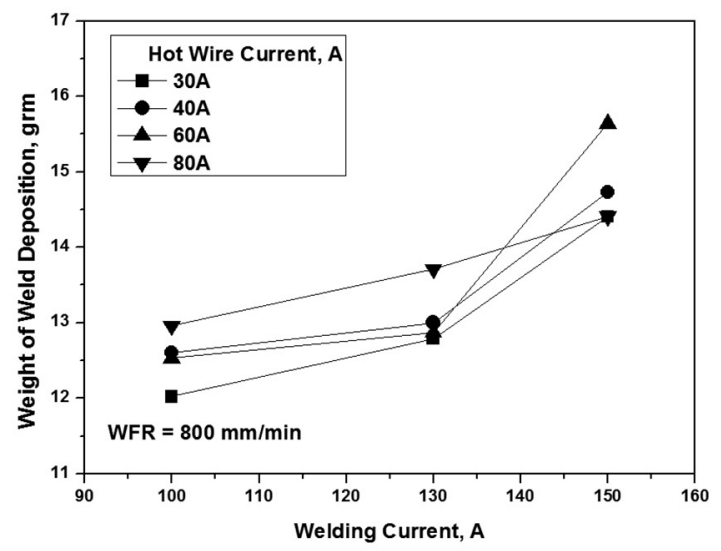

(a)

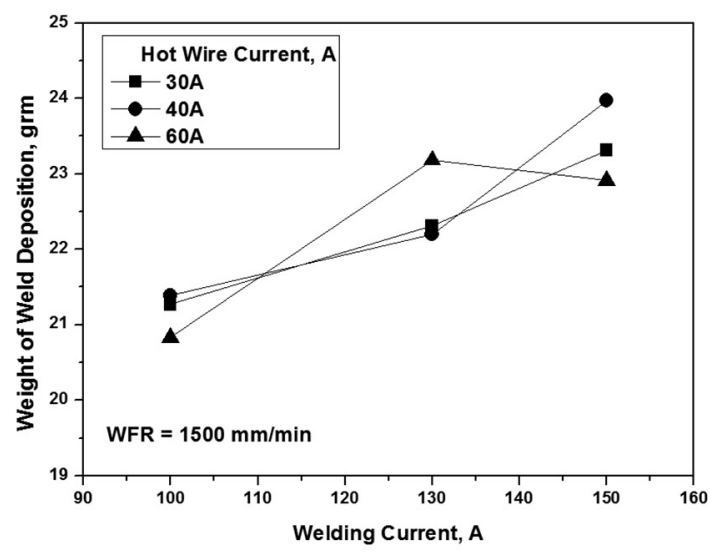

(b)

Figure 9: Effect of welding current on weight of weld deposition under different hot wire current (a) WFR $=800 \mathrm{~mm} / \mathrm{min}$ and (b) WFR $=1500 \mathrm{~mm} / \mathrm{min}$.

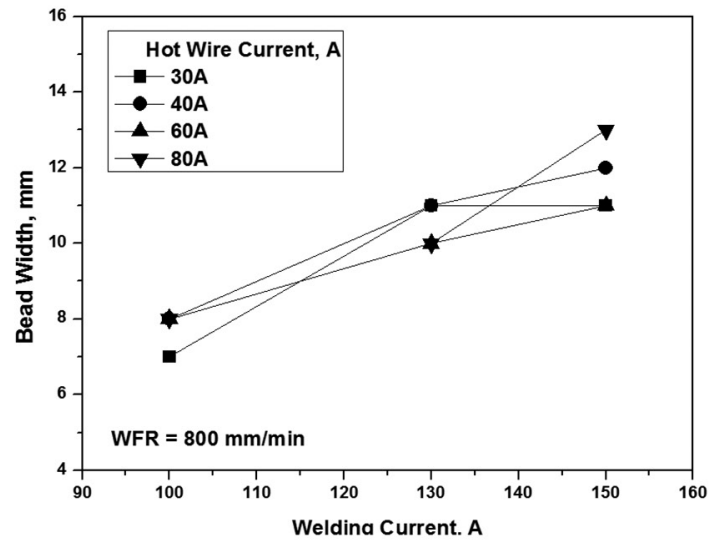

(a)

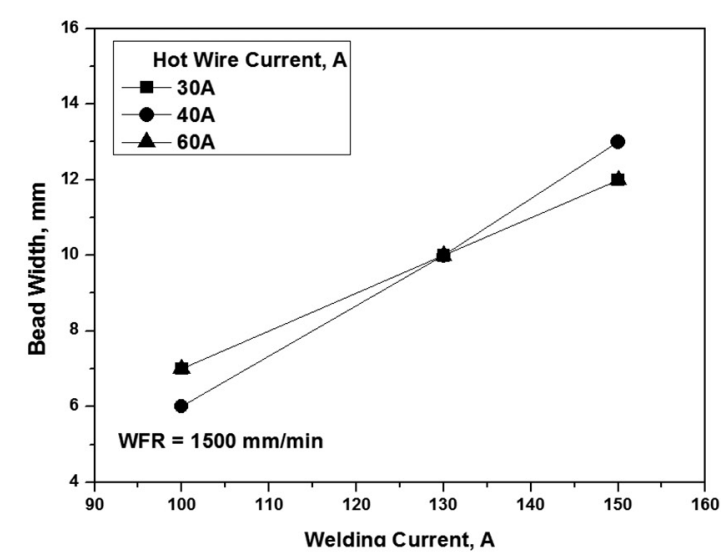

(b)

Figure 10: Effect of welding current on bead width under different hot wire current (a) WFR $=800 \mathrm{~mm} / \mathrm{min}$ and (b) WFR $=1500 \mathrm{~mm} / \mathrm{min}$.

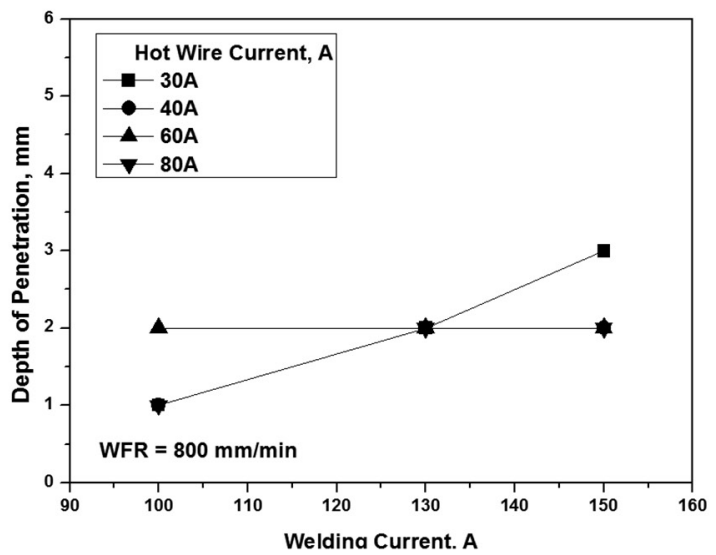

(a)

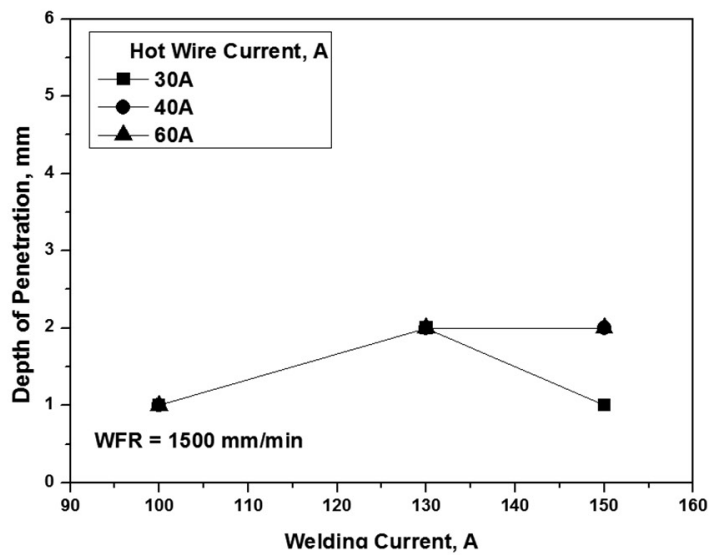

(b)

Figure 11: Effect of welding current on depth of penetration under different hot wire current (a) WFR $=800 \mathrm{~mm} / \mathrm{min}$ and (b) WFR $=$ $1500 \mathrm{~mm} / \mathrm{min}$. 


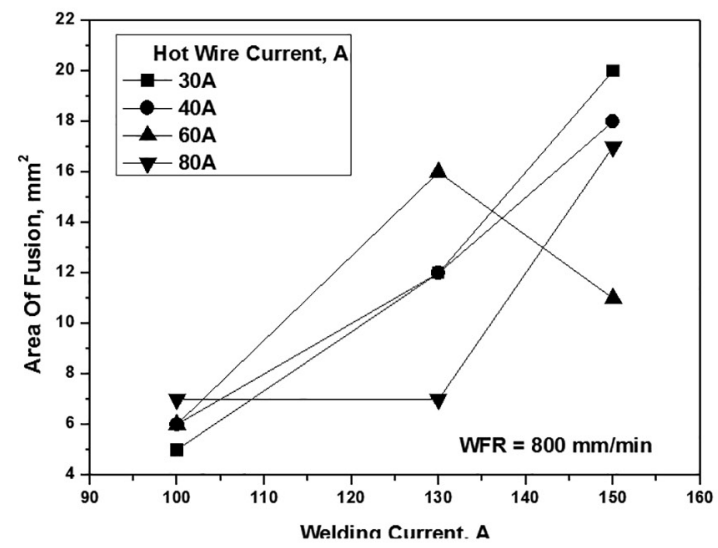

(a)

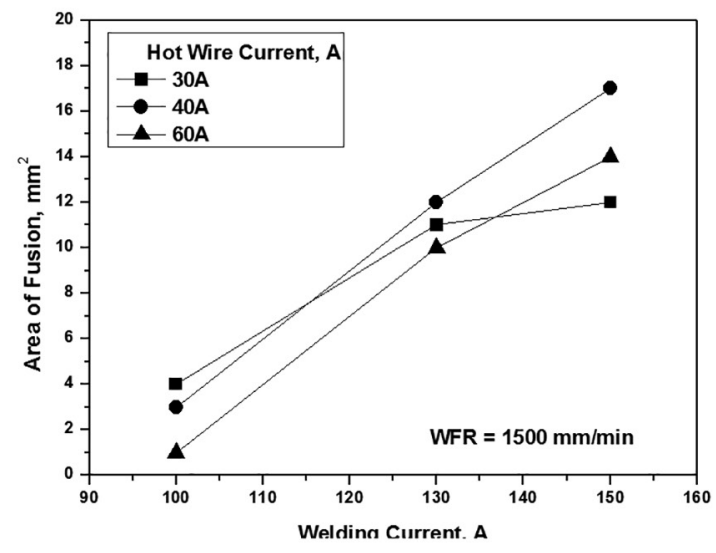

(b)

Figure 12: Effect of welding current on area of fusion under different hot wire current (a) WFR $=800 \mathrm{~mm} / \mathrm{min}$ and (b) WFR $=1500 \mathrm{~mm} / \mathrm{min}$.

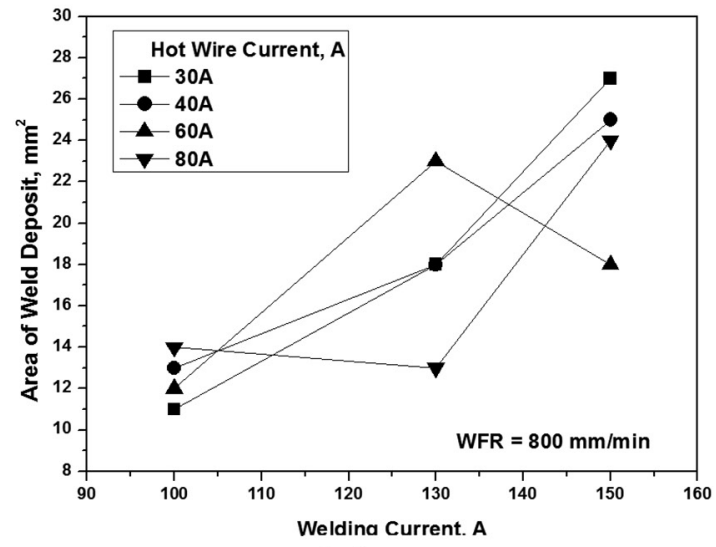

(a)

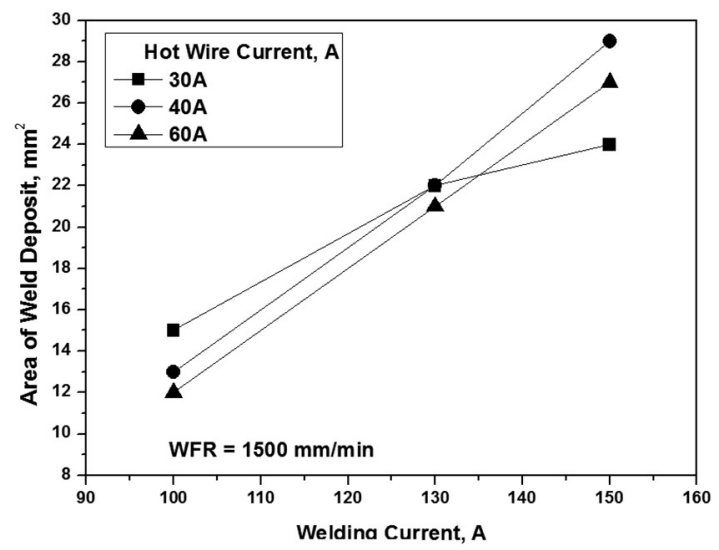

(b)

Figure 13: Effect of welding current on area of weld deposition under different hot wire current (a) WFR $=800 \mathrm{~mm} / \mathrm{min}$ and (b) WFR $=1500 \mathrm{~mm} / \mathrm{min}$.

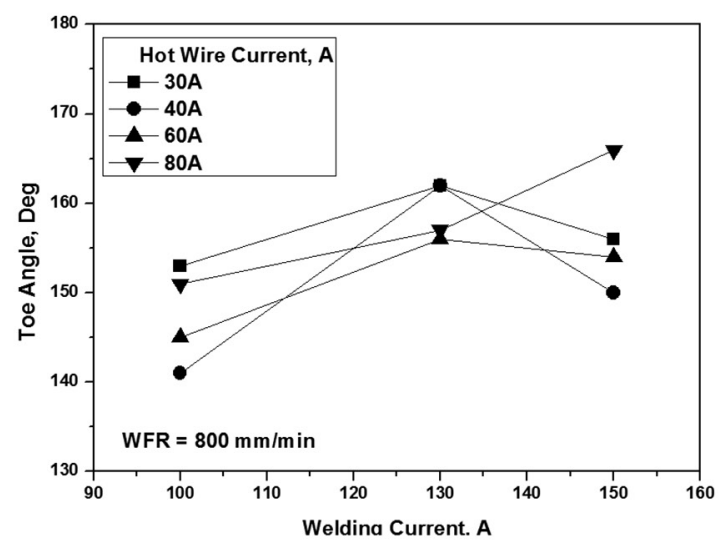

(a)

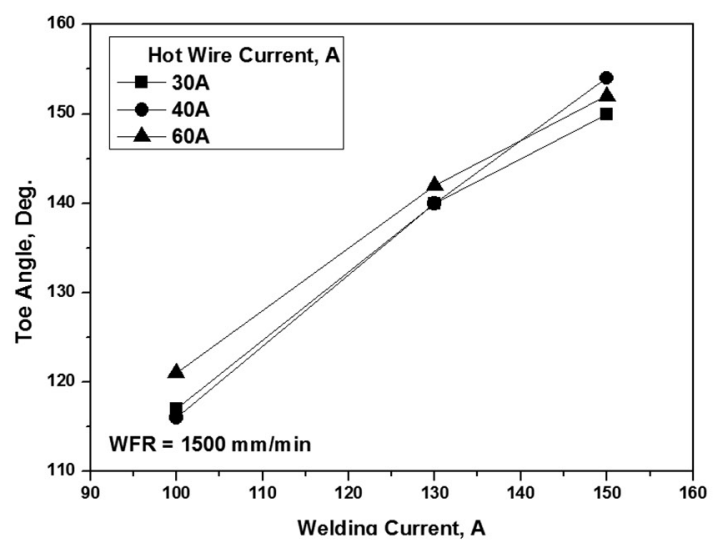

(b)

Figure 14: Effect of welding current on toe angle under different hot wire current (a) WFR $=800 \mathrm{~mm} / \mathrm{min}$ and (b) WFR $=1500 \mathrm{~mm} / \mathrm{min}$. 
Table 4: Results of Super 304H weld joint prepared by HW-GTAW process.

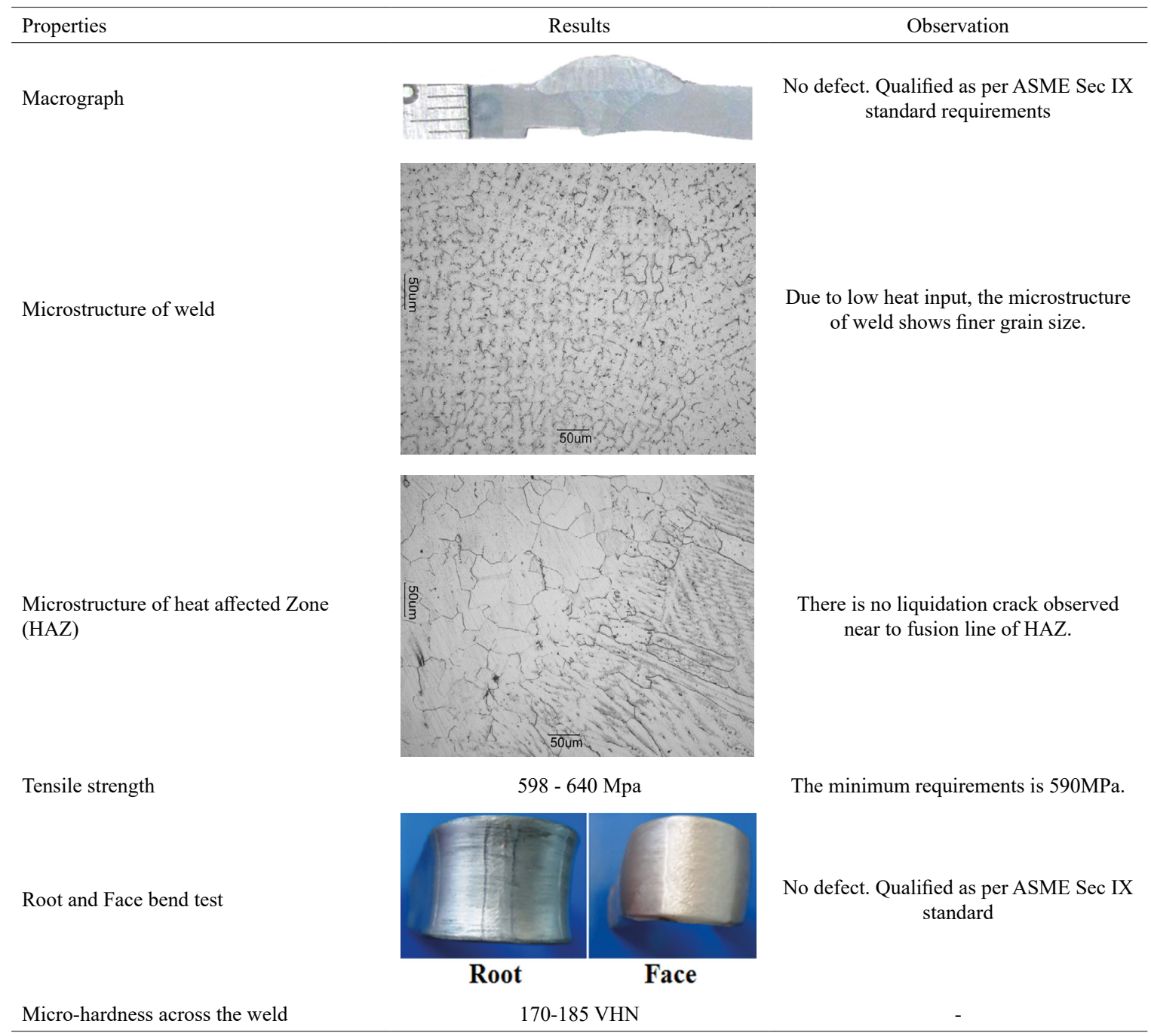

\section{Acknowledgements}

The authors thankfully acknowledge Welding Research Institute, BHEL Trichy, India, for carrying out welding trials.

\section{References}

1. Lashchenko GI. Combined fusion welding technologies (Review). The Paton Welding Journal. 2012;8:29-35.

2. Pai A, Albert SK, Kumar P, Mitra TK, Sogalad I, Basavarajappa S. Evaluation of mechanical properties of modified $9 \mathrm{Cr}$-1Mo welds produced by narrow gap hot wire and cold wire gas tungsten arc welding processes for 500MWe PFBR system generators. Indian Welding Journal. 2014;47(3):49-57.

3. Pai A, Sogalad I, Albert SK, Prabhat Kumar, Mitra TK, Basavarajappa S. Comparison of microstructure and properties of modified $9 \mathrm{Cr}-1 \mathrm{Mo}$ welds produced by narrow gap hot wire and cold wire gas tungsten arc welding processes. Procedia Materials Science. 2014;5:1482-1491.
4. DebRoy T, David SA. Physical processes in fusion welding. Reviews of Modern Physics. 1995;67(1):85-112.

5. Devakumaran K, Rajasekaran N, Ghosh PK. Process characteristics of inverter type GMAW power source under static and dynamic operating conditions. Materials and Manufacturing Processes. 2012;27(12):1450-1456.

6. Rohith Joseph, SalaiSelvaRani M, Devakumaran K, Venkateswaran PR. Investigations on the performance characteristics of GMAW power sources. Indian Welding Journal. 2013;46(1):50-64.

7. Liu W, Liu S, Ma J, Kovacevic R. Real-time monitoring of the laser hot-wire welding process. Optics \& Laser Technology. 2014;57:66-76.

8. Pavan AHV, Vikrant KSN, Ravibharath R, Singh K. Development and evaluation of SUS 304H - IN 617welds for advanced ultra supercritical boiler applications. Materials Science and Engineering: A. 2015;642:32-41.

9. Lancaster JF. The Physics of welding. $1^{\text {st }}$ ed. Oxford: Pergamon Press; 1984. 
10. Saenger JF. Gas tungsten arc hot wire welding - A versatile new production tool. Welding Journal. 1970;49(5):363-371.

11. Agrawal BP, Ghosh PK. Thermal modelling of multi-pass narrow gap pulse current GMA welding by single seam per layer deposition technique. Materials and Manufacturing Processes. 2010;25(11):1251-1268.

12. Radaij D. Heat effects on welding. 1 $^{\text {st }}$ ed. New York: Springer; 1992.

13. Cao J, Gong Y, Zhu K, Yang ZG, Luo XM, Gu FM. Microstructure and mechanical properties of dissimilar materials joints between T92 martensitic and S304H austenitic steels. Materials and Design. 2011;32(5):2763-2770.
14. Vekeman J, Huysmans S, De Bruycker E. Weldability assessment and high temperature properties of advanced creep resisting austenitic steel DMV304HCu. Weld World. 2014;58(6):873-882.

15. David SA, Siefert JA, Shingledecker JP, DuPont JN. Weldability and weld performance of candidate nickel base superalloys for advanced ultrasupercritical fossil power plants part I: fundamentals. Science and Technology of Welding and Joining. 2015;20(7):532-552.

16. Muthusamy C, Karuppiah L, Paulraj S, Kandasami D, Kandhasamy R. Effect of Heat Input on Mechanical and Metallurgical Properties of Gas Tungsten Arc Welded Lean Super Martensitic Stainless Steel. Materials Research. 2016;19(3):572-579. 